\title{
Effect of Hydroxymethylated Experiment on Complexing Capacity of Sodium Lignosulfonate
}

\author{
Ting Zhou \\ School of Nuclear Technology and Chemistry \& Biology, Hubei University of Science and \\ Technology, Xianning, Hubei, China \\ 452920189@qq.com
}

\begin{abstract}
Keywords: Hydroxymethylation; complexion; metal ions; sodium lignosulfonate
Abstract. Influence of hydroxymethylated reaction in different conditions on complexing capacity of sodium lignosulfonate (SL) with $\mathrm{Cu}(\mathrm{II}), \mathrm{Zn}(\mathrm{II})$ and $\mathrm{Mg}(\mathrm{II})$ was investigated. By single factor experiment, the optimal reaction conditions were as follows: dosage of formaldehyde was $0.22 \mathrm{~g} \cdot(\mathrm{g}$ $\mathrm{SL})^{-1}$, temperature was $60 \sim 70^{\circ} \mathrm{C}, \mathrm{pH}$ was 11.0 . Under the optimum condition, the amount of complexed $\mathrm{Cu}, \mathrm{Zn}$ and $\mathrm{Mg}$ of hydroxymethylated sodium lignosulfonate (HSL) increased by $34.9 \%$, $23.3 \%$ and $18.9 \%$ respectively, compared to the original SL. Moreover, the total hydroxyl group content of SL increased after reaction, which suggested that the main contributor to complexing capacity improvement was total hydroxyl content.
\end{abstract}

\section{Introduction}

Sodium lignosulfonate (SL), the waste of acid pulping, has good water solubility and complexing capacity because of the large amount of hydrophilic and chelating groups, which can complex polyvalent metal ions to form water-soluble chelates. The complexing property of lignin and its derivatives can be used as water treatment agent, chelated fertilizer and flocculants. So it's important to investigate the complexing capacity of SL and find ways to increase its complexing capacity.

Many factors can affect complexing capacity of SL, for example, the most important factor affecting complexing capacity of massoniana alkali lignin with metal element was hydroxyl group content [1]. Adilson R[2] also found that the complexing capacity of lignin increased with hydroxyl and carbonyl content. Some chemical reactions were used to increase the complexing capacity of raw SL, for instance, the methylol content of lignin model compound increased after hydroxymethylated reaction[3]. Based on it, I try to increase the hydroxyl group content to improve complexing capacity of SL by hydroxymethylated modification, and then optimal reaction conditions can be obtained.

\section{Experimental}

Reagents. Sodium lignosulfonate (SL), supplied by Tongdao Paper Making Co. Ltd., Hunan, China, was purified by ion exchange and ultrafiltration. Formaldehyde $(37 \%), \mathrm{NaOH}, \mathrm{MgCl}_{2} \cdot 6 \mathrm{H}_{2} \mathrm{O}$, $\mathrm{ZnSO}_{4} \cdot 7 \mathrm{H}_{2} \mathrm{O}$ and $\mathrm{CuSO}_{4} \cdot 5 \mathrm{H}_{2} \mathrm{O}$ used in this paper were of recognized analytical grade.

Hydroxymethylated experiment of SL. A certain amount of SL was dissolved in deionized water and the mass concentration made up to $25 \mathrm{wt} \%$, then the solution was transferred to a $250 \mathrm{ml}$ flask. Sodium hydroxide was added in it to adjust the $\mathrm{pH}$, and then formaldehyde was dropped in the solution and reacted for 2 hours at a set temperature. Lastly, the product was dried at $50^{\circ} \mathrm{C}$ and named hydroxymethylated sodium lignosulfonate (HSL).

Intrinsic viscosity measurement of SL. The intrinsic viscosity measurement of SL in deionized water was performed with an Ubbelohde viscometer at $25^{\circ} \mathrm{C}$. The time of deionized water and tested SL flowing through capillary column was recorded. Each measurement conducted three continuous tests, which should be repeated until the relative standard deviation for any sample was within 5\%. The intrinsic viscosity formula was shown in Eq. 1 and Eq. 2.

$$
[\eta]=\frac{\sqrt{2 \eta_{\mathrm{r}}-2-2 \ln \eta_{\mathrm{r}}}}{c} .
$$




$$
\eta_{r}=\frac{\rho t}{\rho_{0} t_{0}} \text {. }
$$

Where, $[\eta]$ was intrinsic viscosity of $\mathrm{SL}, \mathrm{mL} / \mathrm{g}, \eta_{r}$ was reduced viscosity, $c$ was the mass concentration of SL solution, $\mathrm{g} / \mathrm{mL}, t$ was the time of SL solution flowing through capillary column, $\mathrm{s}$, $t_{0}$ was the time of deionized water flowing through capillary column, $\mathrm{s}, \rho$ was density of $\mathrm{SL}$ at $25^{\circ} \mathrm{C}$, $\mathrm{g} / \mathrm{mL}, \rho_{0}$ was density of deionized water at $25^{\circ} \mathrm{C}$, which was $1.00 \mathrm{~g} / \mathrm{mL}$.

Content determination of phenolic hydroxyl and carboxyl in SL. The phenolic hydroxyl and carboxyl content of SL were measured by an automatic potentiometric titrator (Type 809 Titrando, Metrohm Corp., Switzerland) [4].

Complexed metal analysis[5]. This method is based on AOAC Official Method 983.03 (1986). In brief, $\mathrm{Mg}(\mathrm{II}) \mathrm{SL}, \mathrm{Zn}(\mathrm{II}) \mathrm{SL}$ and $\mathrm{Cu}(\mathrm{II}) \mathrm{SL}$ complexes were prepared from SL and the addition of appropriate amount of metal solution $\left(\mathrm{MgCl}_{2} \cdot 6 \mathrm{H}_{2} \mathrm{O}\right.$ or $\mathrm{ZnSO}_{4} \cdot 7 \mathrm{H}_{2} \mathrm{O}$ or $\left.\mathrm{CuSO}_{4} \cdot 5 \mathrm{H}_{2} \mathrm{O}\right)$. In complexes, the mass ratio of $\mathrm{SL}$ to $\mathrm{Mg}(\mathrm{II}), \mathrm{Zn}(\mathrm{II})$ and $\mathrm{Cu}(\mathrm{II})$ were all 1:0.05. Each complex sample was adjusted to $\mathrm{pH} 6.0$ with $0.1 \mathrm{M} \mathrm{HCl}$ and the volume made up to $100 \mathrm{~mL}$ with deionized water. At this time, the concentration of SL was $c_{0}, \mathrm{~g} / \mathrm{L}$. Then the solution was transferred to a stoppered erlenmeyer flask and shaken for 12 hours at $25^{\circ} \mathrm{C}$ in an oscillator (THZ-C-1). $20 \mathrm{~mL}$ of sample solution was pipetted into a beaker and two drops of $\mathrm{H}_{2} \mathrm{O}_{2}$ were added in it. Then the $\mathrm{pH}$ increased to a given value (the $\mathrm{pH}$ value of $\mathrm{Mg}(\mathrm{II}) \mathrm{SL}, \mathrm{Zn}(\mathrm{II}) \mathrm{SL}$ and $\mathrm{Cu}(\mathrm{II}) \mathrm{SL}$ were 11.0, 10.0 and 9.0, respectively). The $\mathrm{pH}$ was increased again to the above value after $30 \mathrm{~min}$ and the solution was allowed to stand for 24 hours. Then samples were centrifuged at $5000 \mathrm{r} / \mathrm{min}$ at $25^{\circ} \mathrm{C}$ for $30 \mathrm{~min}$. The supernatant was collected and diluted $\mathrm{n}$ times with deionized water. The complexed metal element was determined after the removal of organic compound by FAAS (Z-2300, Hitachi Corp., Japan). The formula was shown in Eq. 3.

$$
\Gamma(\mathrm{mg} / \mathrm{g})=\frac{n c_{t}}{c_{0}} \text {. }
$$

Where, $\Gamma$ was the content of metal ions complexed by SL or HSL, $\mathrm{mg} \cdot(\mathrm{g} \text { sample })^{-1}, c_{0}$ was the concentration of the original SL solution, $\mathrm{g} / \mathrm{L}, c_{t}$ was the concentration of metal ion measured by FAAS, mg/L.

\section{Results and Discussion}

Effect of the content of formaldehyde on hydroxymethylated experiment of SL. When temperature was $70^{\circ} \mathrm{C}$, $\mathrm{pH}$ was 11.0 , the influence of different concentration of formaldehyde on the molecular conformation of HSL was studied. The dosage of formaldehyde were $0.15,0.22,0.30 \mathrm{~g} \cdot(\mathrm{g}$ $\mathrm{SL})^{-1}$ in this experiment. When the content of formaldehyde was $0.30 \mathrm{~g} \cdot(\mathrm{g} \mathrm{SL})^{-1}$, the FTIR spectrum (Tensor 27 Infrared Spectrometer, Bruke Corp., Germany) of SL and HSL were shown in Fig. 1.

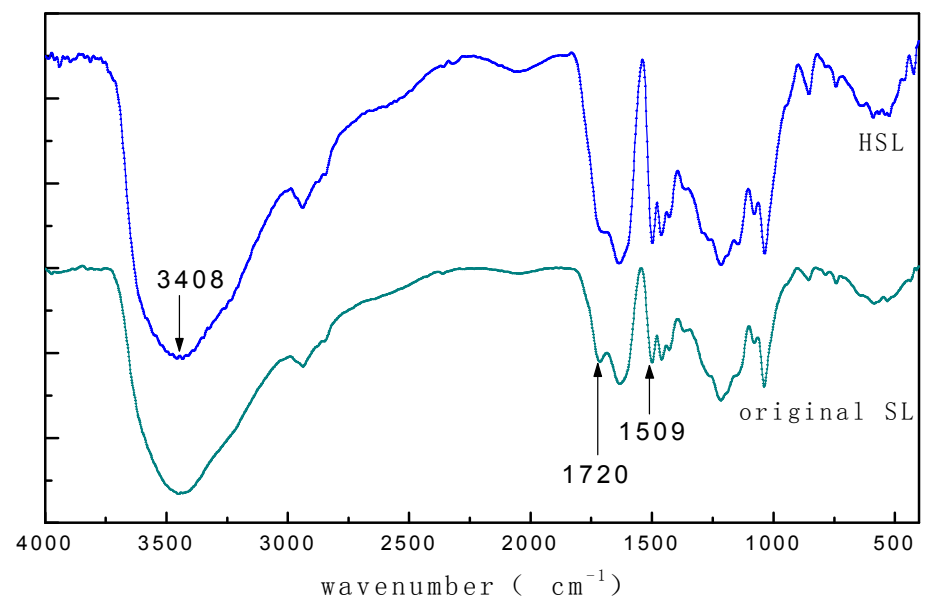

Fig. 1 FTIR spectrum of SL and HSL

As shown in Fig. 1, compared to SL, the absorbed vibration of HSL increases at $1509 \mathrm{~cm}^{-1}$, which means that the content of aromatic ring structure in lignin increased. This result may be caused by the 
polycondensation reaction between SL and formaldehyde in alkali condition[6]. Moreover, the absorption peak strength at about $1720 \mathrm{~cm}^{-1}$ is almost the same before and after reaction, which indicates that the carbonyl content substantially unchanged. The peak area of band at $3408 \mathrm{~cm}^{-1}$ and $1509 \mathrm{~cm}^{-1}$ are compared in order to determine the total hydroxyl content of SL and HSL, and results are given in Table 1.

Table 1 IR peak area of lignosulfonates at the wave numbers $3408 \mathrm{~cm}^{-1}$ and $1509 \mathrm{~cm}^{-1}$

\begin{tabular}{cccc} 
& \multicolumn{2}{c}{ Peak area } & \\
\cline { 2 - 3 } lignosulfonates & $\mathrm{S}_{3408} / \mathrm{S}_{1509}$ \\
& $\mathrm{~S}_{1509}$ & $\mathrm{~S}_{3408}$ & \\
\hline Original SL & 6.94 & 264.97 & 38.18 \\
HSL & 3.35 & 184.81 & 55.17 \\
\hline
\end{tabular}

It can be seen from Table 1, the total hydroxyl content of SL increases after hydroxymethylated experiment. Moreover, phenolic hydroxyl and carboxyl content and intrinsic viscosity of SL were measured and results were given in Table 2.

Table 2 Effect of the dosage of formaldehyde on the molecular conformation of HSL

\begin{tabular}{cccc}
\hline $\begin{array}{c}\text { dosage of } \\
\text { formaldehyde } \\
\left(\mathrm{g} \cdot(\mathrm{g} \mathrm{SL})^{-1}\right)\end{array}$ & $\begin{array}{c}\text { carboxyl content } \\
(\mathrm{mmol} / \mathrm{g})\end{array}$ & $\begin{array}{c}\text { phenolic } \\
\text { hydroxyl content } \\
(\mathrm{mmol} / \mathrm{g})\end{array}$ & $\begin{array}{c}\text { intrinsic } \\
\text { viscosity } \\
(\mathrm{mL} / \mathrm{g})\end{array}$ \\
\hline 0 & 2.02 & 0.98 & 5.29 \\
0.15 & 2.00 & 0.60 & 5.81 \\
0.22 & 2.04 & 0.64 & 5.60 \\
0.30 & 2.01 & 0.76 & 5.75 \\
\hline
\end{tabular}

As shown in Table 2, intrinsic viscosity slightly increases after modification, which indicates that the relative molecular weight of SL is increased, inferring that polycondensation reaction between SL and formaldehyde occurres in alkali condition. The carbonyl content substantially unchange after reaction, which is similar to the results of FTIR spectrum measurement. The phenolic hydroxyl content decreased and total hydroxyl content increases, indicating that alcoholic hydroxyl content of SL increases after reaction.

Fig. 2 shows that the complexing capacity of different SLs with $\mathrm{Mg}, \mathrm{Zn}$ and $\mathrm{Cu}$. The complexing capacity of SL is different with different metal ions. The complexing capacity of HSL with $\mathrm{Mg}, \mathrm{Zn}$ and $\mathrm{Cu}$ are all higher than that of SL. The total hydroxyl content increases, relative molecular weight of SL slightly increases and carbonyl content substantially unchange, so it can be inferred that the increasing total hydroxyl group content of SL is the main contributor to complexing capacity improvement.

The maximum values of HSL complexed with $\mathrm{Zn}, \mathrm{Mg}$ and $\mathrm{Cu}$ are $45.18,47.77$ and $45.72 \mathrm{mg} \cdot(\mathrm{g}$ sample $)^{-1}$, which increases by $11.9 \%, 17.5 \%$ and $34.9 \%$ respectively, compared to the original SL. The complexing capacity of HSL with the above three metal ions firstly increases and then decreases with the dosage of formaldehyde, and it come to a head when the dosage is $0.22 \mathrm{~g} \cdot(\mathrm{g} \mathrm{SL})^{-1}$. The more the formaldehyde, the easier Cannizzaro reaction and aggregation of SL occurres, which hinder the development of hydroxymethylated experiment. Thus, excessive dosage of formaldehyde goes against complexing capacity improvement of SL, and the optimum content of formaldehyde is 0.22 $\mathrm{g} \cdot(\mathrm{g} \mathrm{SL})^{-1}$.

Effect of temperature on hydroxymethylated experiment of SL. When the dosage of formaldehyde was $0.22 \mathrm{~g} \cdot(\mathrm{g} \mathrm{SL})^{-1}$, $\mathrm{pH}$ was 11.0 , the influence of temperature on the complexing capacity of HSL was studied and results were shown in Fig. 3. It can be seen from Fig. 3, the maximum values of HSL complexed with $\mathrm{Zn}, \mathrm{Mg}$ and $\mathrm{Cu}$ are 47.25, 48.33 and $45.72 \mathrm{mg} \cdot(\mathrm{g} \text { sample })^{-1}$, which increases by $23.3 \%, 18.9 \%$ and $34.9 \%$ respectively, compared to the original SL. The complexing capacity of HSL with $\mathrm{Mg}$ changes very little with changing temperature, and it reaches maximum at $60^{\circ} \mathrm{C}$. But temperature has great impact on the complexing capacity of HSL with Zn and $\mathrm{Cu}$. The complexing capacity of HSL with $\mathrm{Zn}$ and $\mathrm{Cu}$ firstly increases and then decreases with 
temperature and come to a head at $60^{\circ} \mathrm{C}$ and $70^{\circ} \mathrm{C}$ respectively. So the optimum temperature is $60 \sim 70^{\circ} \mathrm{C}$.

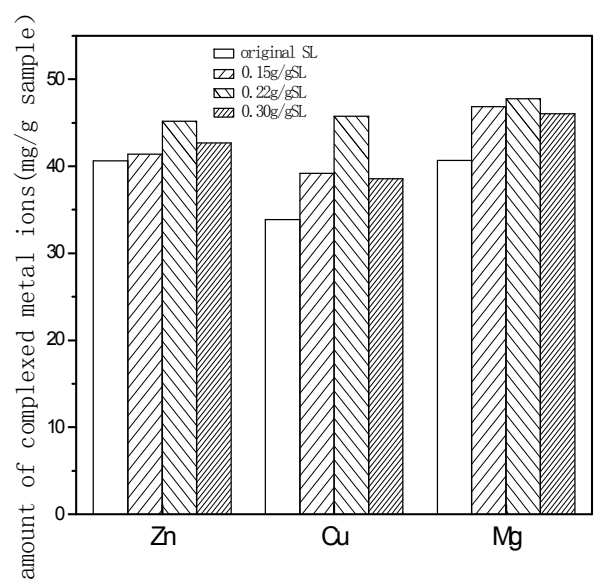

Fig. 2 Influence of the content of formaldehyde on the chelating capacity of HSL

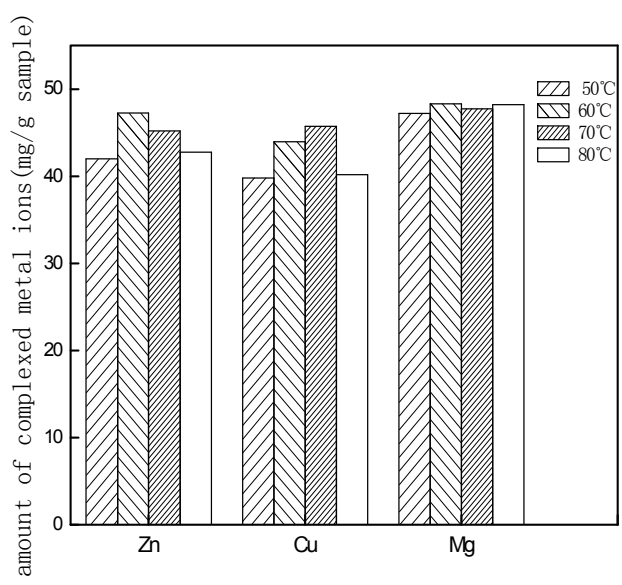

Fig. 3 Influence of the temperature on chelating on the chelating capacity of HSL

Effect of system pH on hydroxymethylated experiment of SL. When the dosage of formaldehyde was $0.22 \mathrm{~g} \cdot(\mathrm{g} \mathrm{SL})^{-1}$, temperature was $60^{\circ} \mathrm{C}$, the change of system $\mathrm{pH}$ before and after reaction was investigated. When the initial system $\mathrm{pH}$ is $9 \sim 11$, the decrement of $\mathrm{pH}$ is about 1.0 , and the $\mathrm{pH}$ value decreases by 1.8 when original $\mathrm{pH}$ is 12 . It indicates that the lager the initial $\mathrm{pH}$, the more of $\mathrm{pH}$ decrement after reaction. The result infers that it is easy for formaldehyde to produce formic acid and methanol under high alkali condition due to the Cannizzaro reaction.

Effect of $\mathrm{pH}$ on complexing capacity of HSL is further studied and results are shown in Fig. 4. The maximum values of HSL complexed with $\mathrm{Zn}, \mathrm{Mg}$ and $\mathrm{Cu}$ are $47.25,48.85$ and $43.95 \mathrm{mg} \cdot(\mathrm{g} \text { sample })^{-1}$, which increases by $23.3 \%, 20.1 \%$ and $29.6 \%$ respectively, compared to the original SL. The $\mathrm{pH}$ has little impact on the complexing capacity of HSL with $\mathrm{Zn}, \mathrm{Mg}$ and $\mathrm{Cu}$. When $\mathrm{pH}$ value is 11.0, the amount of complexed $\mathrm{Zn}$ and $\mathrm{Cu}$ reaches maximum. The amount of complexed $\mathrm{Mg}$ is $48.33 \mathrm{mg} \cdot(\mathrm{g}$ sample $)^{-1}$ at $\mathrm{pH} 11.0$, which is close to $48.85 \mathrm{mg} \cdot(\mathrm{g} \text { sample })^{-1}$ at $\mathrm{pH} 9.0$. Thus, the optimum reaction $\mathrm{pH}$ value is 11.0 .

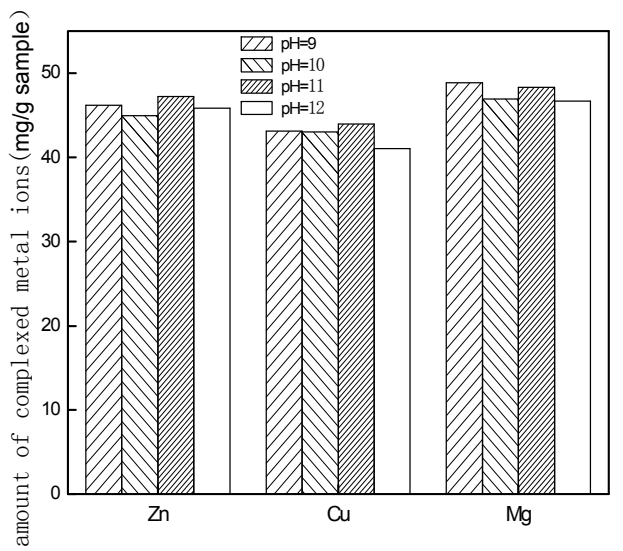

Fig. 4 Influence of the $\mathrm{pH}$ on the chelating capacity of HSL

\section{Conclusions}

The complexing capacity of SL with metal ions is improved after hydroxymethylated reaction. Results suggest that the superior reaction conditions are as follows: the dosage of formaldehyde is $0.22 \mathrm{~g} \cdot(\mathrm{g} \mathrm{SL})^{-1}$, temperature is from 60 to $70^{\circ} \mathrm{C}, \mathrm{pH}$ is 11.0 . Under this optimum condition, the complexing capacity of $\mathrm{HSL}$ with $\mathrm{Zn}, \mathrm{Mg}$ and $\mathrm{Cu}$ respectively increases by $23.3 \%, 18.9 \%$ and $34.9 \%$. Furthermore, the total hydroxyl group content and intrinsic viscosity of HSL are increased, the 
carbonyl content remains almost the same after reaction. This study shows that the main contributor to complexing capacity improvement is increasing total hydroxyl group content of SL.

\section{References}

[1] Chun He, Zhong Li, Zhenxia Zhao, et al. Adsorption Properties of A Low-cost Lignin Adsorbent for Removal of Heavy Metal Ions $\mathrm{Pb}^{2+}$, J. Ion Exchange and Adsorption, 22 (2006) 481-488. In Chinese

[2] Goncalves, A.R., Benar, P. Hydroxymethylation and oxidation of organosolv lignins and utilization of the products, J. Bioresource technology, 2001, 79 (2): 103-111.

[3] Jun Wang. Study on the Crossliking Reaction of Lignin Sand Stabilizer, D. Nanjing: Nanjing Forestry University, 2011. In Chinese

[4] Mingsong Zhou, Kai Huang, Xueqing Qiu, et al. Content Determination of Phenolic Hydroxyl and Carboxyl in Lignin by Aqueous Phase Potentiometric Titration, J.CIESC Journal, 63 (2012) 258-265. In Chinese

[5] AOAC. Offical Method 983.03. Iron (chelated) in Iron Chelate Concentrates. Atomic Absorption Spectrophotometric Method. Offical Methods of Analysis of the Association of Offical Analytical Chemists; Arlington, VA. (1983)

[6] Wenjuan Bu. Study on Synthesis and Applied of Alkali Lignin Modified Phenol Formaldehyde, D. Guangzhou: South China University of Technology, 2011. In Chinese 